\title{
COMMENTARY
}

\section{Statins: a role in infected critically ill patients?}

\author{
Jonathon Dean Truwit* \\ See related research by Terblanche et al., http://ccforum.com/content/15/1/R74
}

\begin{abstract}
Terblanche and colleagues add to the ongoing controversy over the role, if any, for statins in patients with sepsis. The authors note that statins fail to prevent progression to organ dysfunction in critically ill patients. However, like most publications, the study is retrospective and stimulates the controversy but fails to resolve it. The time has come for robust randomized controlled clinical trials.
\end{abstract}

Should statins be a part of the sepsis treatment regimen? Not yet, suggest Terblanche and colleagues [1] in the previous issue of Critical Care. Pleiotropic effects beyond cholesterol reduction have been reported in statins [2-5]. These anti-inflammatory and immunomodulatory effects, seen in models of sepsis and acute lung injury (ALI), provide the basis for statin therapy in critically ill patients [6-10]. Observational data regarding the potential beneficial pleiotropic effects of statins in sepsis and ALI have been presented, and findings variously support and refute the beneficial effects of statins in the infected patient. While meta-analysis suggests a potential benefit, the few prospective randomized trials that have been published have conflicting conclusions [11-13].

The retrospective study by Terblanche and colleagues [1], who followed mechanically ventilated patients without significant non-pulmonary end-organ disease over their intensive care unit (ICU) stay, adds to the controversy. Patients receiving statins had higher APACHE II (Acute Physiology and Chronic Health Evaluation II) scores $(20.3$ versus $17.8 ; P<0.0001)$ and were older $(67.4$ versus 55.5 years; $P<0.0001)$. Those receiving statins also had more severe respiratory SOFA (Sepsis-related Organ Failure Assessment) scores and were more likely to have some degree of renal and cardiovascular dysfunction at baseline. Statin administration was not associated with

*Correspondence: truwit@virginia.edu

Pulmonary and Critical Care Medicine, University of Virginia, Box 800793 , Charlottesville, VA 22908, USA reduced incidence of non-pulmonary acute organ failure or mortality but was associated with longer ICU and hospital stays. A greater proportion of the statin group had alanine aminotransferase (ALT) values of greater than three times the upper limit of normal (ULN) (11.6\% versus $4.8 \% ; P=0.0002)$. These elevations were brief in longevity, and no clinical untoward effects were noted. It is difficult to understand the ramifications, as the median time of drug delivery was just 3 days, limiting both beneficial effects and harmful ones. The median dose of simvastatin, the predominant statin, was just $20 \mathrm{mg}$, and only one third of patients had statins started on day 1; both circumstances potentially reduced the opportunity to prevent the progression of organ dysfunction.

Kruger and colleagues [14] randomly assigned patients on statins after admission for sepsis to atorvastatin $20 \mathrm{mg}$ (equivalent to simvastatin $40 \mathrm{mg}$ ) or placebo. Patients were admitted to either acute care wards or ICUs, whereas patients in the study by Terblanche and colleagues were admitted to the ICU or were mechanically ventilated. Continuation of statin therapy was not protective with regard to sepsis or markers of inflammation. Compared with subjects in the study by Terblanche and colleagues, subjects received more doses of study drug, and 3 out of 150 patients had an elevated ALT of greater than five times the ULN. Two of the three were receiving atorvastatin. No patients had creatine kinase $(\mathrm{CK})$ values exceeding 10 times the ULN. Kruger and the Australian and New Zealand Intensive Care Society (ANZICS) have just concluded a study randomly assigning ICU patients with severe sepsis to atorvastatin or placebo (ACTRN12607000028404).

Craig and colleagues [15] evaluated patients with ALI from all causes and randomly assigned 60 patients to simvastatin $80 \mathrm{mg} /$ day or placebo until extubation or 14 days, whichever occurred first. While this study was not powered to detect differences in mortality, a significant reduction in SOFA scores was noted at day 14, suggesting that statin administration hastens the resolution of end-organ damage. SOFA scores fell from 10.2 to 4.2 in the statin group and from 10.4 to 8.8 in the placebo group $(P=0.01)$. Doses were administered $88 \%$ and $82 \%$ of days in the statin and placebo groups, respectively, and no differences in elevated CK, ALT, or 
aspartate aminotransferase (AST) values between groups were noted. This population had higher APACHE II scores than those in the study by Terblanche and colleagues, and mean values were 25.1 and 23.3 in the statin and placebo groups, respectively. Daniel McAuley and the Irish Critical Care Trials Group have initiated a larger randomized controlled trial that has ventilator-free days (VFDs) as the primary outcome (ISRCTN88244364).

The National Heart, Lung, and Blood Institute (NHLBI) ARDSNet has initiated the SAILS (Statins for Acutely Injured Lungs from Sepsis) trial (NCT00979121). In this study, subjects who have ALI and who are statin-free for 72 hours are randomly assigned to rosuvastatin $20 \mathrm{mg}$ (equivalent to simvastatin $80 \mathrm{mg}$ ) or placebo. The primary outcome is mortality, and secondary outcomes include VFDs, organ failure-free days, ICU-free days, and toxicity.

Some questions regarding statin administration in patients with presumed infections and systemic inflammatory response syndrome, sepsis, severe sepsis, or ALI remain unanswered:

1. Can statins reduce mortality?

2. Are statins effective in preventing or reducing severity of end-organ damage?

3. Are statins effective in hastening the resolution of endorgan damage?

4. If the answer to any of these questions is yes, then

a. Which statin is most effective and safest?

b. What dose is most effective and safest?

c. Do patients have to be on maintenance statins before developing critical illness?

It is time to turn away from retrospective and observational studies or meta-analysis and test the plausible rationales that have been put forth. Indeed, several randomized clinical trials have been initiated to address some of these questions in patients with sepsis or ALI.

\section{Abbreviations}

ALI, acute lung injury; ALT, alanine aminotransferase: APACHE II, Acute

Physiology and Chronic Health Evaluation II; CK, creatine kinase; ICU, intensive care unit; SOFA, Sepsis-related Organ Failure Assessment; ULN, upper limit of normal; VFD, ventilator-free day.

\section{Competing interests}

JDT is the principal investigator for the SAILS trial mentioned above.
Published: 31 March 2011

References

1. Terblanche MJ, Pinto R, Whiteley C, Brett S, Beale R, Adhikari NKJ: Statins do not prevent acute organ failure in ventilated ICU patients: single-centre retrospective cohort study. Crit Care 2011, 15:R74.

2. Liao JK, Laufs U: Pleiotropic effects of statins. Annu Rev Pharmacol Toxicol 2005, 45:89-118

3. Weitz-Schmidt G: Statins as anti-inflammatory agents. Trends Pharmacol Sci 2002, 23:482-486.

4. Gao F, Linhartova L, Johnston AM, Thickett DR. Statins and sepsis. Br J Anaesth 2008, 100:288-298.

5. Terblanche M, Almog Y, Rosenson RS, Smith TS, Hackam DG: Statins: panacea for sepsis? Lancet Infect Dis 2006, 6:242-248

6. Jacobson JR, Barnard JW, Grigoryev DN, Ma SF, Tuder RM, Garcia JG: Simvastatin attenuates vascular leak and inflammation in murine inflammatory lung injury. Am J Physiol Lung Cell Mol Physiol 2005, 288:L1026-1032.

7. Merx MW, Liehn EA, Graf J, van de Sandt A, Schaltenbrand M, Schrader J, Hanrath P, Weber C: Statin treatment after onset of sepsis in a murine model improves survival. Circulation 2005, 112:117-124.

8. Mueller HC, Hellwig K, Rosseau S, Tschernig T, Schmiedl A, Gutbier B, Schmeck B, Hippenstiel S, Peters H, Morawietz L, Suttorp N, Witzenrath M: Simvastatin attenuates ventilator-induced lung injury in mice. Crit Care 2010, 14:R143.

9. Jain MK, Ridker PM: Anti-inflammatory effects of statins: clinical evidence and basic mechanisms. Nat Rev Drug Discov 2005, 4:977-987.

10. Shyamsundar M, McKeown ST, O'Kane CM, Craig TR, Brown V, Thickett DR, Matthay MA, Taggart CC, Backman JT, Elborn JS, MCAuley DF: Simvastatin decreases lipopolysaccharide-induced pulmonary inflammation in healthy volunteers. Am J Respir Crit Care Med 2009, 179:1107-1114.

11. Janda S, Young A, Fitzgerald JM, Etminan M, Swiston J: The effect of statins on mortality from severe infections and sepsis: a systematic review and meta-analysis. J Crit Care 2010, 25:656.e7-22.

12. Tleyjeh IM, Kashour T, Hakim FA, Zimmerman VA, Erwin PJ, Sutton AJ, Ibrahim $\mathrm{T}$ : Statins for the prevention and treatment of infections: a systematic review and meta-analysis. Arch Intern Med 2009, 169:1658-1667.

13. Falagas ME, Makris GC, Matthaiou DK, Rafailidis PI: Statins for infection and sepsis: a systematic review of the clinical evidence. J Antimicrob Chemother 2008, 61:774-785.

14. Kruger PS, Harward ML, Jones MA, Joyce CJ, Kostner KM, Roberts MS, Venkatesh B: Continuation of statin therapy in patients with presumed infection: a randomised controlled trial. Am J Respir Crit Care Med 2010 Oct 19. [Epub ahead of print].

15. Craig TR, Duffy MJ, Shyamsundar M, McDowell C, O'Kane C, Elborn JS, McAuley DF: A randomized clinical trial of hydroxymethylglutaryl-CoA reductase inhibition for acute lung injury (The HARP study). Am J Respir Crit Care Med 2010 Sep 24. [Epub ahead of print].

doi:10.1186/cc10086

Cite this article as: Truwit JD: Statins: a role in infected critically ill patients? Critical Care 2011, 15:145 